\title{
Effects of Maleimide-Polyethylene Glycol-modified Human Hemoglobin (MP4) on Tissue Necrosis in SKH1-Hr Hairless Mice
}

\author{
O. Goertz ${ }^{1}$, M. H. Kirschner ${ }^{4}$, H. Lilienfein ${ }^{1}$, P. Babilas ${ }^{2}$, H. U. Steinau ${ }^{1}$, C. Andree ${ }^{5}$, A. Daigeler ${ }^{1}$, \\ A. Stachon ${ }^{3}$, H. Homann ${ }^{1}$, S. Langer ${ }^{1}$ \\ ${ }^{1}$ Department of Plastic and Hand Surgery, Burn Center, University Hospital Bergmannsheil, Ruhr-University Bochum, Germany \\ ${ }^{2}$ Department of Dermatology, Regensburg University Medical Center, Germany \\ ${ }^{3}$ Institute of Clinical Chemistry, Transfusion, and Laboratory Medicine, Ruhr- University Bochum, Germany \\ ${ }^{4}$ BBD Aesculap GmbH, Tuttlingen, Germany \\ ${ }^{5}$ Sana Hospital, Düsseldorf, Germany
}

\begin{abstract}
Objective: Tissue hypoxia after blood loss, replantation and flap reperfusion remains a challenging task in surgery. Normovolemic hemodilution improves hemorheologic properties without increasing oxygen carrying capacity. Red blood cell transfusion is the current standard of treatment with its attendant risks. The aim of this study was to investigate the potential of the chemically modified hemoglobin, MP4, to reduce skin flap necrosis and its effect on selected blood markers and kidneys.

Materials and Methods: Tissue ischemia was induced in the ear of hairless mice $(n=26)$. Hemodilution was performed by replacing one third of blood volume with the similar amount of MP4, dextran, or blood. The extent of non-perfused tissue was assessed by intravital fluorescent microscopy.

Results: Of all groups, MP4 showed the smallest area of no perfusion (in percentage of the ear \pm SEM: $16.3 \% \pm 2.4)$, the control group the largest $(22.4 \% \pm$ 3.5). Leukocytes showed a significant increase in the MP4 and dextran group (from 8.7 to 13.6 respectively $\left.15.4 * 10^{9} / 1\right)$. On histology no changes of the kidneys could be observed.

Conclusion: MP4 causes an increase of leukocytes, improves the oxygen supply of the tissue and shows no evidence of renal impairment.
\end{abstract}

Key words: MP4, hairless mice, intravital fluorescent microscopy, oxygen carrier, free hemoglobin, intracardiac access, hemodilution

\section{INTRODUCTION}

The occurrence of tissue hypoxia after blood loss, replantation, transplantation and flap reperfusion remains a challenging task in surgery today. In particular, the occurrence of tissue necrosis in skin flaps is a major problem in microvascular surgery. Impaired microcirculation is known to be a frequent cause of ischemia/reperfusion injury [1-3]. The perfusion depends on an equilibrium of blood pressure and heart rate, vessel diameter and length, blood viscosity, and interstitial fluid pressure, which is regulated by myogenic autoregulation, metabolic and neural control mechanisms and many other factors [4]. Alteration of one of these parameters can impair the perfusion of the tissue. Vasoconstriction has been a major problem in the clinical development of $\mathrm{Hb}$-based $\mathrm{O}_{2}$ carriers. It narrows the inner vessel diameter, weakening the already impaired microcirculation $[5,6]$. With the conjugation of hemoglobin with polyethylene glycol the hemoglobin lost its vasoconstrictive responses [7].

In the clinical setting, normovolemic hemodilution is a well established method for improving the hemorheologic properties of the supplying blood without increasing the oxygen carrying capacity. The current alternative consists of red blood cell transfusion which still involves time consuming type and cross matching, transmission of diseases, allergic reactions and short shelf life. Besides the imbalance between recipients and donors and the treatment of transfusion associated complications, it creates an enormous increase in costs that underlines the desirability of replacing red blood cell solutions with artificial oxygen carriers. Intravenously administered artificial oxygen carriers are intended to increase the reduced $\mathrm{O}_{2}$ carrying capacity of blood in the case of acute severe anemia, i.e. hemorrhagic shock or extreme normovolemic hemodilution. Two groups of artificial $\mathrm{O}_{2}$ carriers are currently being investigated: ultrapurified, stroma-free hemoglobin solutions of human or bovine origin and synthetically produced perfluorocarbon emulsions (PFC). Chemically modified hemoglobin solutions may be administered in large amounts and are suitable for $1: 1$ replacement of blood losses in case of hemorrhage as well as for isovolemic exchange of blood [8].

The advantages of artificial oxygen carriers vs. red blood cells are:

- reduced risk of transmitting infections because of stroma-free hemoglobin solutions

- absence of immunologic risks

- long storage with no reduction in effectiveness

- increased availability (about four times the amount of MP4 out of one unit of outdated human red blood cells) [9]. 


\section{Maleimide-Polyethylene GlyCol-Modified HEMOGLOBIN (MP4)}

MP4 is human hemoglobin modified by surface conjugation of monofunctional maleimide-activated $5-\mathrm{kDa}$ polyethylene glycol to surface thiol groups [7]. The modification has prolonged the plasma retention time and has redressed the hypertensive and nephrotoxic effect of former solutions [10]. MP4 has a low hemoglobin concentration, a slightly lower viscosity and is hyperoncotic to blood. Contrary to almost all other hemoglobin solutions it possesses an increased oxygen affinity [7]. The high oxygen affinity seems to be counterproductive at first in the treatment of ischemia, but it can be assumed that, because of its high oxygen affinity, MP4 reaches the capillary level with a respectively higher load of oxygen. In accordance with a higher blood-tissue gradient, the release of oxygen is facilitated [11].

Experimental studies on animals during hemorrhagic shock and extreme hemodilution have proven that MP4 has a superior effect on the microcirculation, compared to conventional therapies with crystalloidal or colloidal solutions, by increasing tissue oxygenation and functional capillary density $[12,13]$. To the present day no studies have investigated this effect under local induced ischemia.

The aim of the present study is to investigate the effects of MP4 on the microcirculation in ischemic tissue and its potential to reduce skin flap necrosis compared to dextran 70 and control groups, as well as its effect on blood parameters and kidney morphology.

\section{Materials And Methods}

\section{ANIMALS}

Hairless mice $(\mathrm{SKH}-1 / \mathrm{hr}, \mathrm{n}=26)$ aged between 6 and 7 weeks and weighing $24-27 \mathrm{~g}$ were obtained (Charles River, Sulzfeld, Germany) one week prior to the experiments and were housed one per cage at $24^{\circ} \mathrm{C}$ in a 12 hour dark/light cycle with standard laboratory food and water ad libitum. The animals underwent general anesthesia on each occasion during the actual flap creation as well as during the subsequent investigations. All experiments have been carried out with ethical committee approval and meet the standards required by the UKCCCR guidelines. In addition, each procedure was approved by the regional authorities according to German animal care regulations, which comply with the international guidelines of animal care and use in scientific experiments (AZ 50.8735.1).

\section{AnEsthesia}

All animals underwent general anesthesia performed by spontaneous inhalation of Isoflurane- $\mathrm{N}_{2} \mathrm{O}\left(\mathrm{F}_{\mathrm{i}} \mathrm{O}_{2}: 0.33\right.$, $\mathrm{F}_{\mathrm{i}} \mathrm{N}_{2} \mathrm{O}: 0.66,0.015 \mathrm{~L} / \mathrm{L}$ Isoflurane, Forene ${ }^{\mathbb{R}}$, Abbott $\mathrm{GmbH}$, Wiesbaden, Germany). To avoid hypothermia, mice were placed onto a heated acryl glass observation platform (Fig. 1). To create a single-pedicle arterial skin flap model, the mouse ear was first extended onto the platform by three microsurgical loops $\left(10 / 0\right.$ Surgipro ${ }^{\circledR}$, Tyco $^{\circledR}$, Germany), which were pulled through the peripheral parts of the ear and fixed by three threads
(5/0 Surgipro ${ }^{\circledR}$, Tyco $^{\circledR}$, Germany). For improved translucency, isotonic saline $\left(\mathrm{NaCl} 0.9 \%\right.$ B. Braun Ecobag $\left.{ }^{\circledR}\right)$ was applied between ear and platform to derive advantage from adhesive forces.

\section{Applications}

For contrast enhancement, the anesthetized animals received an intravenous bolus injection over the tail

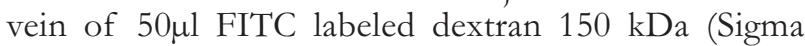
Chemicals Co., St. Louis, MO, USA) serving as a plasma marker for intravital fluorescent microscopy (tube 29G, B.Braun, Melsungen, Germany); during the four investigations the animals received altogether $200 \mu$ l of additional fluids intravenously due to the application of the plasma marker. After flap creation, the demarcation line between perfused and non perfused tissue could be directly visualized by intravital microscopy.

\section{FLAP CREATION}

We used the skin flap model of the ear of the hairless mouse [14]. In the past the ear of hairless mice has undergone different processes to investigate their influence on the microcirculation [14-18].

The neurovascular supply of the mouse ear is made up of three bundles leading from the base of the ear to the periphery. To create a single-pedicle skin flap model, the ear was first extended and fixed on the platform, and then four fifths of its caudal base was incised, leaving the flap thus created solely dependent on the anterior neurovascular bundle for its nourishment.

\section{INTRACARDIAC ACCESS}

The intracardiac access for blood withdrawal as well as for application of test solutions has proven in this study to be less invasive, and also offers the advantages of rapid preparation and low infection risk compared to conventional central intravenous access.

Once the anesthetized animal has been placed on its back, the withdrawal was carried out with a syringe (needle diameter 29G) below the xiphoid at an angle of about $15^{\circ}$ towards the median line from right and the same angle versus dorsal in a left-cranial direction under constant aspiration control. The first withdrawal of $500 \mu \mathrm{l}$ was replaced by the same amount of MP4, dextran or blood. After flap creation $100 \mu$ l were again taken to determine the amount of free hemoglobin and the hematocrit in order to check the success of the application. The withdrawal was only performed twice: once after application of MP4, dextran or blood and once after completing the last recordings.

After each procedure the needle could be removed without any subsequent bleeding and the animals showed no reduced condition at any time. Altogether one of 40 animals died during our study accidentally, the heart showed no severe damage.

\section{RECORDINGS}

Before flap creation the unimpaired microcirculation was assessed by intravital fluorescent microscopy (IFM) (Axiotech vario, Carl Zeiss, Oberkochen, Germany). An 


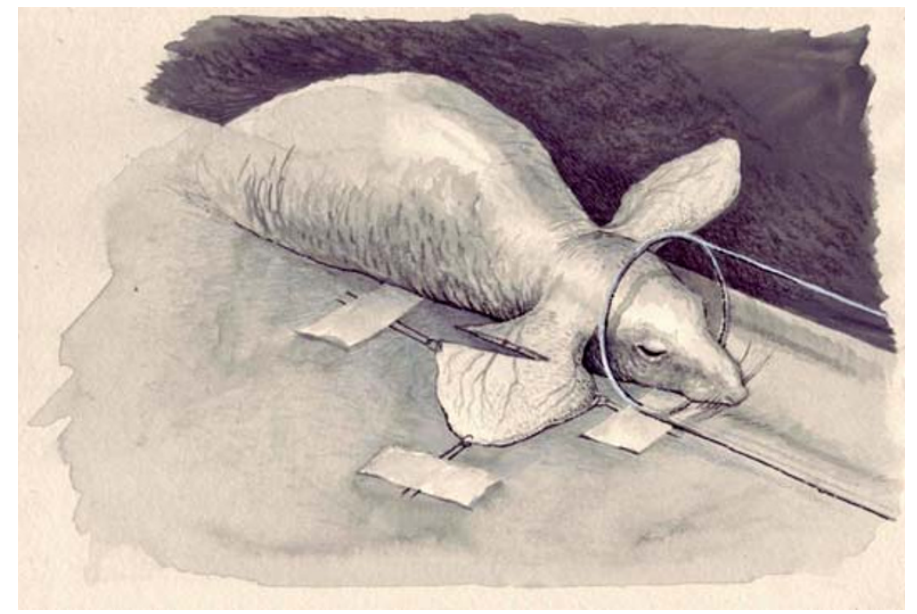

Fig. 1. Tissue ischemia was induced by severing four fifths of the ear at its caudal base, leaving a single pedicle for its nourishment. The snout is lying in an acryl glass tube for general anesthesia performed by spontaneous inhalation of Isoflurane- $\mathrm{N}_{2} \mathrm{O}$.
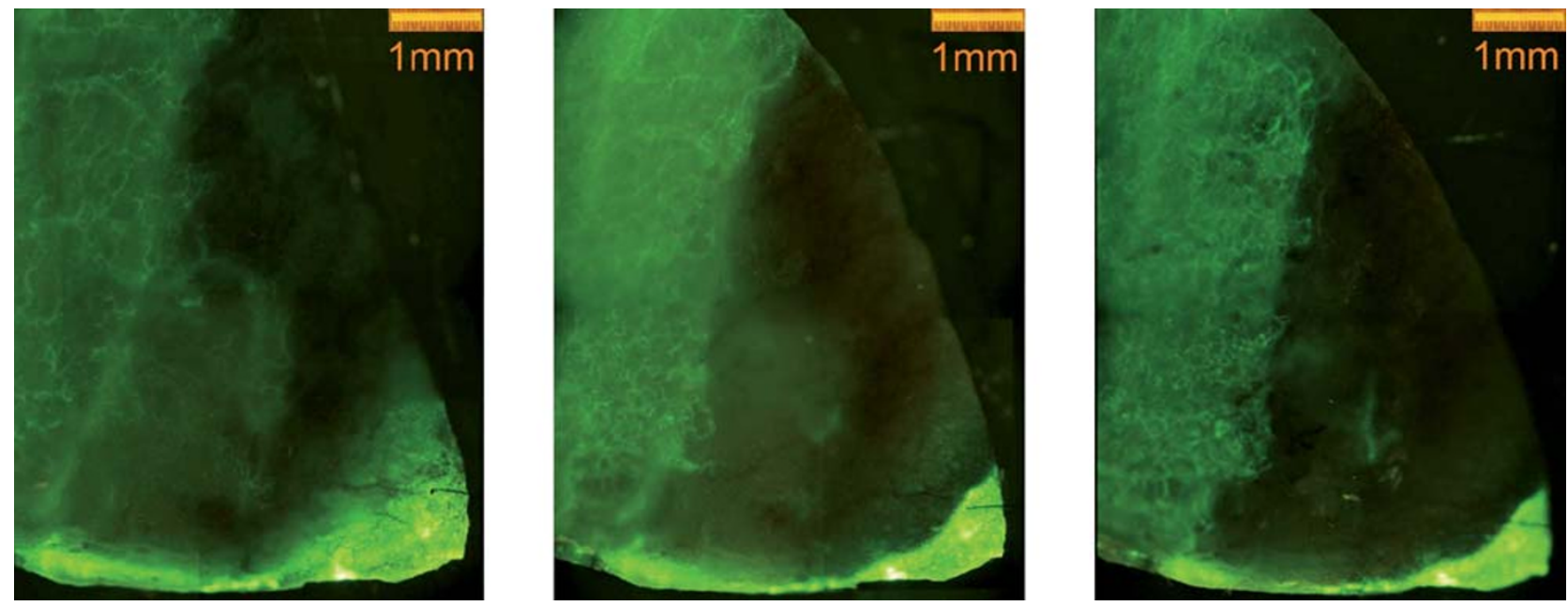

Fig. 2. Non perfused area 24,48 and $72 \mathrm{~h}$ (left to right) after flap creation. The bright area shows perfusion due to the circulating fluorescent dye FITC, whereas the dark area is no longer perfused.
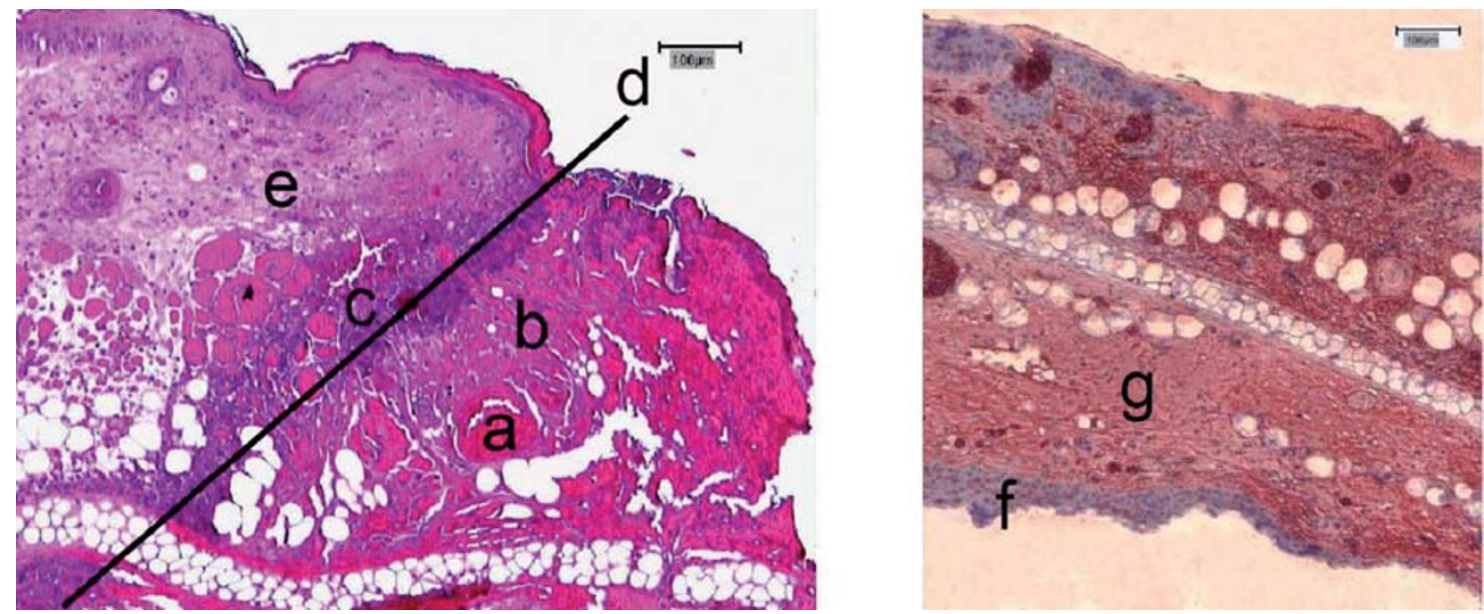

Fig. 3. shows a cross section of the ear of the hairless mouse. On the left in hematoxylin-eosin, on the right in TUNEL staining $72 \mathrm{~h}$ post trauma.The picture on the left shows a cluster of proteins (eosinophilic (a)) in the area of necrosis/no perfusion (b) followed by an area of granulocytes (purple (c)), marking off the vital (e) from the avital (b) tissue; (d) marks the border between vital and avital tissue. TUNEL staining was used to find the exact border of necrotic/apoptotic and vital tissue. The vital cells stain blue (f) and the necrotic/apoptotic cells red (g).

overall view was achieved by a four fold objective resulting in a total magnification of about 52 fold for measurements of the non perfused area (NPA).
In order to be able to differentiate between intravascular occlusion and sufficient blood flow, red blood cell flow was recorded by connecting the micro- 


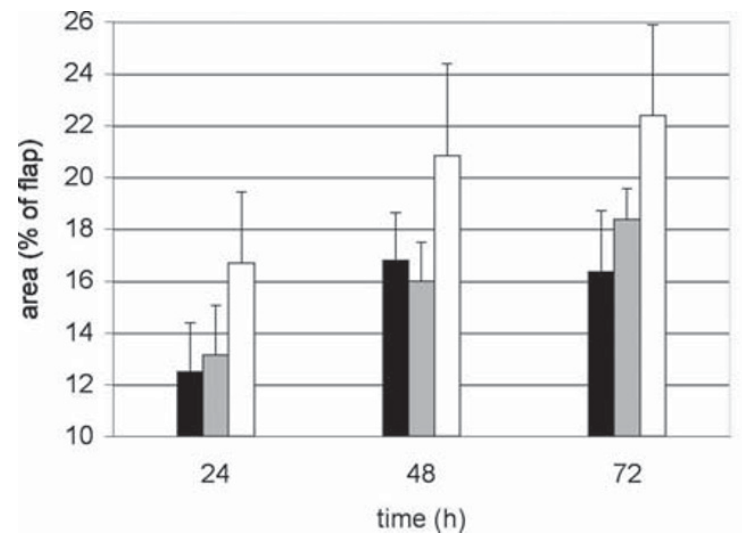

MP4 $(n=10)$

Fig. 4. The figure shows the non perfused area of the ischaemic flap in percentage 24,48 and $72 \mathrm{~h}$ after flap creation with corresponding standard error of the mean. Compared to both other groups MP4 presents the smallest proportion of no perfusion over the whole observation period, whereas the control group demonstrated the most extended NPA at any given observation. However no significance between all groups could be seen.

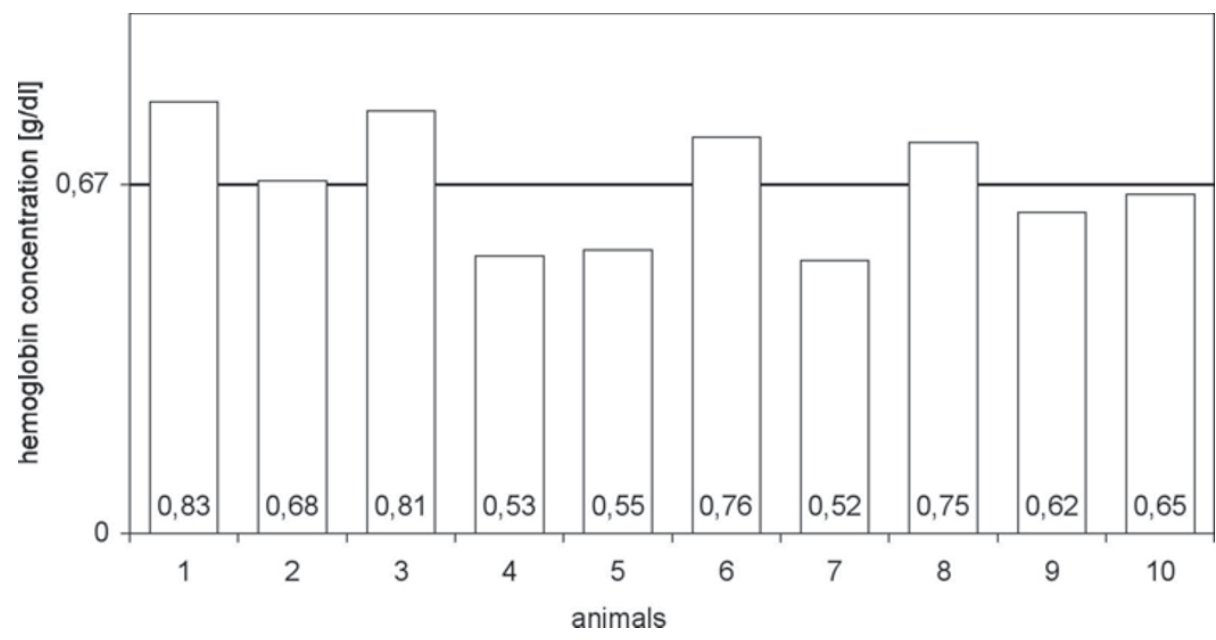

Fig. 5. Amount of free hemoglobin (MP4) five minutes post intracardiac application of MP4. The mean value was $0.67 \mathrm{~g} / \mathrm{dl}$. Data are given for the MP4 group only, no free hemoglobin was found in the other two groups.

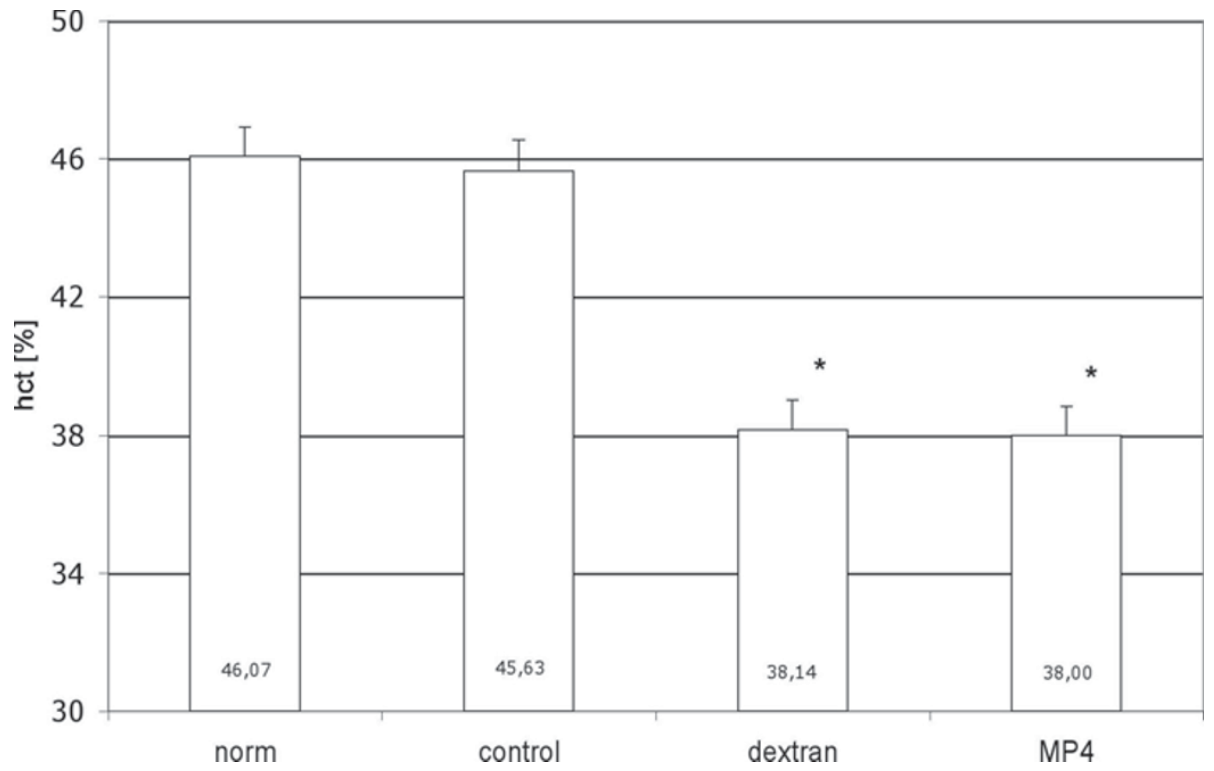

Fig. 6. Percentage of hematocrit $72 \mathrm{~h}$ post intracardiac injection. The value of the MP4 and the dextran group was about $38 \% 72 \mathrm{~h}$ post injection. *significantly different from control group $(\mathrm{p}<0.05)$.

scope with a video camera (AVT-BC 71, AVT-Horn, Aalen, Germany) and a digital camera (Canon EOS D60) and stored on a PC. Vessels with doubtful perfusion on the photo could be checked up on the video later. Because of the magnification no direct overview could be achieved. Therefore 9 separately recorded digital pictures of one ear were stored under a magnification of 300dpi and later assembled into one picture with the help of the computer program Photoshop ${ }^{\circledR}$. Microscopic observations were performed before and after flap creation as well as after 24,48 and $72 \mathrm{~h}$.

\section{MeAsurements}

The measurement of ear size and area of non perfusion was performed after assembling the different pictures with the help of the computer program CapImage ${ }^{\circledR}[19]$. The borderline between perfused and non perfused tissue was well demarked by the contrast en- 


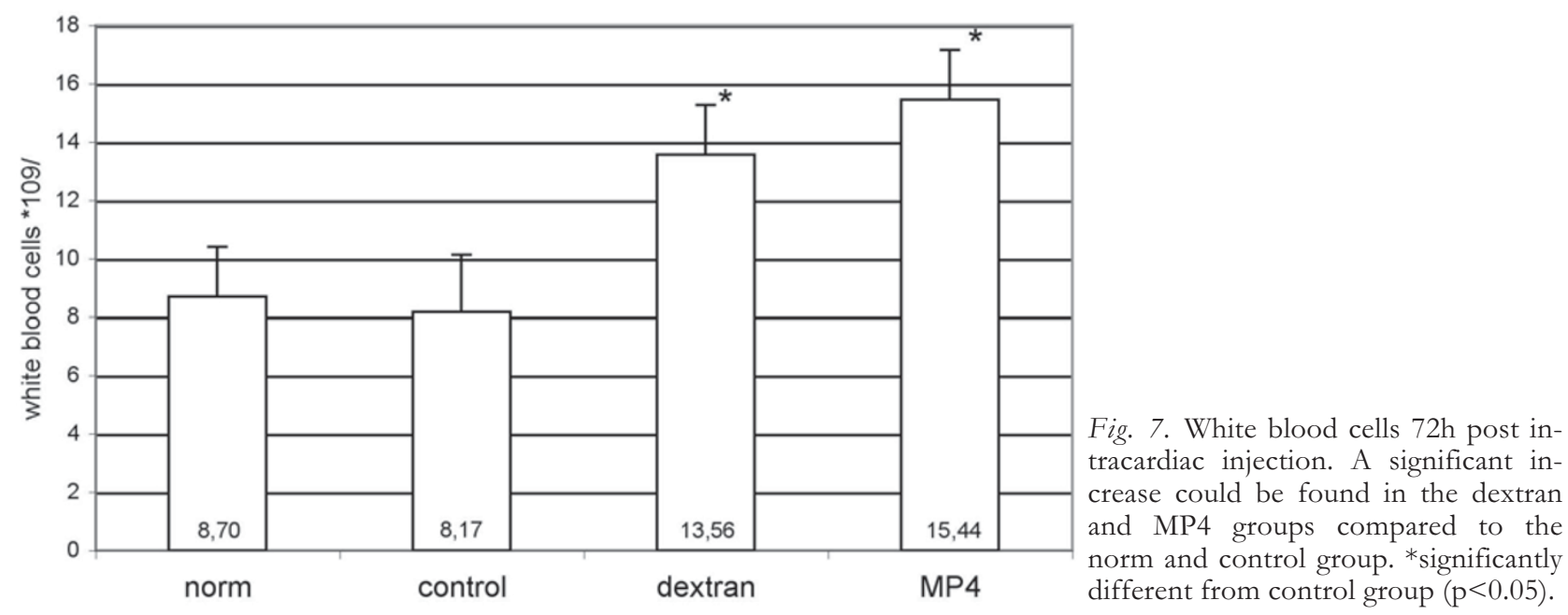

hancement of FITC-dextran (Fig. 2). The measurements were carried out 24, 48 and $72 \mathrm{~h}$ after flap creation. Measurements of nonperfused area are expressed as percentage of the created flap.

The blood analysis was performed using a blood animal counter (scil Vet abc, scil animal care company, Viernheim, Germany) before and after application of the different solutions and on day 3. The free hemoglobin was measured in the laboratory of the Bergmannsheil Hospital, Ruhr-University Bochum (Prof. M. Krieg).

The concentration of MP4 or free hemoglobin respectively was determined by measuring the concentration of free hemoglobin before and after injecting the three solutions (blood, dextran and MP4). Since the control group and the dextran group showed no free hemoglobin, the concentration of free hemoglobin in the MP4 group is assumed to be equal to that in the mouse after injection. The extension of hemodilution was determined by the hematocrit (HCT) before and after giving MP4, dextran and blood. The influence of each solution on blood parameters was then investigated before and after flap creation and after 24 , 48 and $72 \mathrm{~h}$.

\section{STATISTICS}

The commercially available computer program SigmaStat' (Version 2.0, Jandel Scientific, Erkrath, Germany) was used for statistical analysis of the data. Comparisons between different times were performed using the Student's t-test. A p $<0.05$ was considered statistically significant.

\section{RESULTS}

\section{Non Perfused Area}

The smallest area of no perfusion as a percentage of the size of the ear was seen in the MP4 group over the observation period. However, no significance could be demonstrated compared to the dextran and control groups.

The proportion of the NPA in the MP4 group was measured at $12.5 \% \pm 1.9$ after $24 \mathrm{~h}$, increasing to
$16.8 \% \pm 1.5$ after $48 \mathrm{~h}$ and finally dropping to $16.3 \% \pm$ 2.4 after $72 \mathrm{~h}$. However, the proportion in both other groups increased continuously. $24 \mathrm{~h}$ after incision it was measured in the dextran group at $13.2 \% \pm 1.9$, increasing to $16.0 \% \pm 1.5$ (48h) and reaching $18.4 \% \pm$ 1.2 after $72 \mathrm{~h}$. Over the whole observation period the control group showed the largest NPA (24h: 16.7\% \pm 2.7; 48h: $20.8 \% \pm 3.5 ; 72 \mathrm{~h}: 22.4 \% \pm 3.5$ ) (Fig. 4).

The mean blood concentration of free hemoglobin (MP4) in the MP4 group five minutes post intracardiac injection was $0.67 \mathrm{~g} / \mathrm{dl}$ (Fig. 5). In all other groups the free hemoglobin concentration was below the analytical detection limit.

We could not detect any morphological alterations in the cross sections in HE staining of the kidneys in the MP4 group compared with the control group.

The hematocrit in all animals that were given MP4 decreased visibly after injection of the test solution and was measured on average at one third below starting hematocrit (average hematocrit: $46.5 \%$ before, $30.9 \%$ after application of MP4) (Fig. 6). $72 \mathrm{~h}$ after induction of ischemia hematocrit had increased on average up to $38 \%$ (Fig. 6).

In the dextran group, hematocrit dropped a little more than in MP4, on average $28.2 \%$ (average HCT: $46.3 \%$ before, $28.2 \%$ after application of dextran), with an increase $72 \mathrm{~h}$ later up to $38.1 \%$ on average (Fig. 6).

The white blood cells were raised significantly in the dextran and MP4 groups $72 \mathrm{~h}$ post intracardiac injection from 8 to 13.6 respectively 15.4*109/1 (Fig. 7).

Percutaneous intracardiac withdrawal of blood and injection of fluids are safe and feasible without any severe heart muscle damage. To evaluate the morphological damage, histological sections in hematoxylin and eosin staining of the myocardium were carried out: We could detect some muscle damage, but without any clinical importance. Altogether one of 40 animals died accidentally during our study under anasthesia, the heart showed no severe damage.

\section{Discussion}

MP4 shows an obvious tendency to reduce the area of no perfusion compared to the dextran and control 
group, but this is not significant. A reason for the absence of significance could be the surgical alteration of the anatomy due to incision of the ear. Compared to published data of other groups, we measured quite a small area of no perfusion. This could be explained by the use of young mice, which show a higher functional capillary density and a higher rate of anastomosis than older ones $[20,21]$.

In addition, repetitive application and a higher concentration of MP4 could be necessary. An interesting observation was the fact that the area of no perfusion in the MP4 group showed no increase after $48 \mathrm{~h}$, whereas the areas in the other two groups extended between 48 and $72 \mathrm{~h}$. An explanation could be the improvement in oxygenation due to MP4. The tissue in the area of no perfusion died in all three groups, but the tissue that received a minimum of perfusion survived in the MP4 group due to adequate oxygenation, whereas the oxygenation in the two other groups was insufficient and resulted in additional NPA 72 hours post induction of ischemia.

So far the influence of MP4 was investigated only in systemic ischemia as an alternative substitute for blood, which will probably be the main target in the future $[13,22-24]$. In our model we investigated a locally induced ischemia in addition to the hemodilution. The values of less NPA and no further NPA after $48 \mathrm{~h}$ could possibly be improved by higher MP4 concentrations and repetitive applications; studies with a modified design are planned.

We could not find any morphologic changes in the kidneys in the sense of necrotic tubuli or sedimentation of proteins, which are often caused by free hemoglobin [25]. This probably shows the positive effect of the chemical modification of free hemoglobin with polyethylene glycol, which enables the normovolemic hemodilution of about $1 / 3$ of the blood volume in our model without causing any severe damage.

The significant increase in leukocytes in the MP4 and dextran group after $72 \mathrm{~h}$ could not be explained. The animals showed no alterations in behavior and had the same weight compared to the control group. The free hemoglobin could cause reactions of the immune system, but we would wonder about the low variance. Leukocytosis due to dextran is described in rats (colitis after drinking dextran sulphate sodium), in mice and rats after giving dextran sulphate [26-28]. In rhesus monkeys only a transient elevation of aspartate aminotransferase, alanine aminotransferase and lactate dehydrogenase $(\mathrm{LDH})$ was found 3 days after application of MP4, no elevation of leukocytes was detected [23]. In humans a slight elevation of amylase and lipase could be detected [29, 30].

The intracardiac access reduced the mortality compared to central intravenous catheters in our laboratory and was easy to handle. One advantage of our model was the lack of hairs, which allowed a direct view of the xyphoid and facilitated orientation.

In summary, the oxygen carrier MP4 shows a clear tendency to reduce the extent of NPA and therefore necrosis compared to the dextran and control groups, and, in contrast to the other groups, the area of no perfusion in the MP4 group showed no increase after $48 \mathrm{~h}$.
Further studies with different MP4 concentrations and repetitive applications should be conducted to find out whether giving MP4 instead of other commonly used substitutes definitely represents an advantage for flap survival.

Acknowledgements: The authors thank the B.Braun Stiftung, Melsungen, Germany for financial support, Sangart Inc., San Diego, USA, providing MP4, Mark Young, San Diego, USA, for critical reading of the article and giving support during the investigations and C. Cotaru, Newcastle, Australia, for editorial assistance.

\section{REFERENCES}

1. Kerrigan CL: Skin flap failure: pathophysiology. Plast Reconstr Surg 1983, 72(6):766-777.

2. Savitsky JP DJ, Black J, et al: A clinical safety trial of stroma-free hemoglobin. Clin Pharmacol Ther 1978, 23:7380.

3. Rucker M, Roesken F, Schafer T, Spitzer WJ, Vollmar B, Menger MD: In vivo analysis of the microcirculation of osteomyocutaneous flaps using fluorescence microscopy. Br J Plast Surg 1999, 52(8):644-652.

4. Barker JH, Hammersen F, Galla TJ, Bondar I, Zeller P, Menger MD, Messmer K: Direct monitoring of capillary perfusion following normovolemic hemodilution in an experimental skin-flap model. Plast Reconstr Surg 1990, 86(5):946-954.

5. Nolte D, Lehr HA, Sack FU, Messmer K: Reduction of postischemic reperfusion injury by the vasoactive drug buflomedil. Blood Vessels 1991, 28 Suppl 1:8-14.

6. Nolte D, Lehr HA, Messmer K: Adenosine inhibits postischemic leukocyte-endothelium interaction in postcapillary venules of the hamster. Am J Physiol 1991, 261(3 Pt 2):H651-655.

7. Vandegriff KD, Malavalli A, Wooldridge J, Lohman J, Winslow RM: MP4, a new nonvasoactive PEG-Hb conjugate. Transfusion 2003, 43(4):509-516.

8. Kerger H, Tsai AG, Saltzman DJ, Winslow RM, Intaglietta $\mathrm{M}$ : Fluid resuscitation with $\mathrm{O}_{2}$ vs. non- $\mathrm{O}_{2}$ carriers after $2 \mathrm{~h}$ of hemorrhagic shock in conscious hamsters. Am J Physiol 1997, 272(1 Pt 2):H525-537.

9. Habler O, Pape A, Meier J, Zwissler B: [Artificial oxygen carriers as an alternative to red blood cell transfusion]. Anaesthesist 2005, 54(8):741-754.

10. Vandegriff KD, Malavalli A, Minn C, Jiang E, Lohman J, Young MA, Samaja M, Winslow RM: Oxidation and haem loss kinetics of poly(ethylene glycol)-conjugated haemoglobin (MP4): dissociation between in vitro and in vivo oxidation rates. Biochem J 2006, 399(3):463471.

11. Creteur J, Vincent JL: Hemoglobin solutions. Crit Care Med 2003, 31(12 Suppl):S698-707.

12. Wettstein R, Tsai AG, Erni D, Winslow RM, Intaglietta M: Resuscitation with polyethylene glycol-modified human hemoglobin improves microcirculatory blood flow and tissue oxygenation after hemorrhagic shock in awake hamsters. Crit Care Med 2003, 31(6):1824-1830.

13. Drobin D, Kjellstrom BT, Malm E, Malavalli A, Lohman J, Vandegriff KD, Young MA, Winslow RM: Hemodynamic response and oxygen transport in pigs resuscitated with maleimide-polyethylene glycol-modified hemoglobin (MP4). J Appl Physiol 2004, 96(5):1843-1853.

14. Barker JH, Hammersen F, Bondar I, Galla TJ, Menger MD, Gross W, Messmer K: Direct monitoring of nutritive blood flow in a failing skin flap: the hairless mouse ear skin-flap model. Plast Reconstr Surg 1989, 84(2):303313. 
15. Uhl E, Rosken F, Sirsjo A, Messmer K: Influence of platelet-derived growth factor on microcirculation during normal and impaired wound healing. Wound Repair Regen 2003, 11(5):361-367.

16. Kubulus D, Amon M, Roesken F, Rucker M, Bauer I, Menger MD: Experimental cooling-induced preconditioning attenuates skin flap failure. Br J Surg 2005, 92(11): $1432-1438$

17. Kramer GC: Counterintuitive red blood cell substitute-polyethylene glycol-modified human hemoglobin. Crit Care Med 2003, 31(6):1882-1884.

18. Langer S, Goertz O, Steinstraesser L, Kuhnen C, Steinau HU, Homann HH: New model for in vivo investigation after microvascular breakdown in burns: use of intravital fluorescent microscopy. Burns 2005, 31(2):168-174.

19. Klyscz T, Junger M, Jung F, Zeintl H: [Cap image--a new kind of computer-assisted video image analysis system for dynamic capillary microscopy]. Biomed Tech (Berl) 1997, 42(6):168-175.

20. Harder Y, Amon M, Georgi M, Scheuer C, Schramm R, Rucker M, Pittet B, Erni D, Menger MD: Aging is associated with an increased susceptibility to ischaemic necrosis due to microvascular perfusion failure but not a reduction in ischaemic tolerance. Clin Sci (Lond) 2007, 112(8):429440.

21. Vollmar B, Morgenthaler M, Amon M, Menger MD: Skin microvascular adaptations during maturation and aging of hairless mice. Am J Physiol Heart Circ Physiol 2000, 279(4):H1591-1599.

22. Cabrales P, Tsai AG, Winslow RM, Intaglietta M: Extreme hemodilution with PEG-hemoglobin vs. PEG-albumin. Am J Physiol Heart Circ Physiol 2005, 289(6): H2392-2400.

23. Young MA, Malavalli A, Winslow N, Vandegriff KD, Winslow RM: Toxicity and hemodynamic effects after single dose administration of MalPEG-hemoglobin (MP4) in rhesus monkeys. Transl Res 2007, 149(6): 333-342.

24. Winslow RM: Targeted $\mathrm{O}_{2}$ delivery by low-p50 hemoglobin: a new basis for hemoglobin-based oxygen carriers. Artif Cells Blood Substit Immobil Biotechnol 2005, 33(1):1-12.
25. Whitley D, Patterson R, Greenburg AG: Cell-free hemoglobin preserves renal function during normothermic ischemia. J Surg Res 1998, 77(2):187-191.

26. Vicario M, Crespi M, Franch A, Amat C, Pelegri C, Moreto $\mathrm{M}$ : Induction of colitis in young rats by dextran sulfate sodium. Dig Dis Sci 2005, 50(1):143-150.

27. Benner R, Nikkels PG, van Oudenaren A, Wolters EA: Leukocyte mobilization in mice by polyanions. Decline of leukocyte mobilizing capacity after transplantation of lymphoma. Cell Tissue Kinet 1981, 14(3):251-260.

28. Sterling C: Lymphocytosis in rats treated with polyacids. Lymphology 1979, 12(4):253-256.

29. Bjorkholm M, Fagrell B, Przybelski R, Winslow N, Young M, Winslow RM: A phase I single blind clinical trial of a new oxygen transport agent (MP4), human hemoglobin modified with maleimide-activated polyethylene glycol. Haematologica 2005, 90(4):505-515.

30. Olofsson C, Ahl T, Johansson T, Larsson S, Nellgard P, Ponzer S, Fagrell B, Przybelski R, Keipert P, Winslow N et al: A multicenter clinical study of the safety and activity of maleimide-polyethylene glycol-modified Hemoglobin (Hemospan) in patients undergoing major orthopedic surgery. Anesthesiology 2006, 105(6):1153-1163.

Received: December 19, 2008 / Accepted: January 12, 2009

Address for correspondence:

Ole Goertz

Department of Plastic and Hand Surgery

Burn Center

Ruhr- University Bochum,

Buerkle-de-la-Camp Platz 1

4789 Bochum

Germany

Phone: +49-234-302-3599

Fax: +49-234-3026379

E-mail: ole.goertz@rub.de 